\title{
Time to Implement and Aggregate Fluctuations
}

\author{
Jean-Olivier Hairault, François Langot \\ and Franck Portier
}

Respectively Université de Lille I and MAD, Université Paris IX and MAD,

Université de Rouen, CEPREMAP and MAD

First version October 1994

This version May 1996

$n^{\circ} 9606$ 


\title{
Time to Implement and Aggregate Fluctuations
}

\begin{abstract}
In this paper, we slightly modify the canonical $R B C$ model by adding an implementation lag in the technology, to reproduce the fact that consumption is a leading indicator of output. Indeed, we assume that agents have today some information on the realization of the technology shock that will occur tomorrow. Today, inventions are known, and give information on the innovations which will be implemented tomorrow.

The model is estimated and tested on U.S. data by a simulated method of moments, using some suitable reconstructed data that are compatible with that model. The results are in favor of this implementation lag hypothesis: the model is not rejected by US postwar data.
\end{abstract}

\section{Délai de mise en oeuvre et fluctuations macroéconomiques}

\begin{abstract}
Résumé
Dans ce papier, nous modifions à la marge le modèle $R B C$ canonique en introduisant un délai dans la mise en oeuvre des inventions technologiques. Nous supposons que les agents ont dés aujourd'hui de l'information sur la productivité totale des facteurs demain. Aujourd'hui, les inventions sont connues, et donnent de l'information sur ce qui sera effectivement mis en oeuvre demain.

Le modèle est estimé et testé sur données américaines par la méthode des moments simulés, et en utilisant des données reconstruites pour être compatibles avec le modèle. Les résultats sont en faveur de l'hypothèse de délai de mise en oeuvre: le modèle n'est pas rejeté sur données américaines.
\end{abstract}

Keywords: Business Cycle, Simulated Method of Moment, Technological Shocks

JEL code: E32 C15 C52 


\title{
Time to Implement and Aggregate Fluctuations
}

\author{
Jean-Olivier Hairault, François Langot and Franck Portier* \\ First version October 1994 \\ This version May 1996
}

\begin{abstract}
In this paper, we slightly modify the canonical $R B C$ model by adding an implementation lag in the technology, to reproduce the fact that consumption is a leading indicator of output. Indeed, we assume that agents have today some information on the realization of the technology shock that will occur tomorrow. Today, inventions are known, and give information on the innovations which will be implemented tomorrow. The model is estimated and tested on U.S. data by a simulated method of moments, using some suitable reconstructed data that are compatible with that model. The results are in favor of this implementation lag hypothesis: the model is not rejected by US postwar data.
\end{abstract}

\section{Introduction}

What shocks are responsible for economic fluctuations? Cochrane [1994] has recently restated this old question, while improvements in the tools at the disposal of the macroeconomists (stochastic general equilibrium, time series

* Respectively Université de Lille I and MAD, Université Paris IX and MAD, Université de Rouen, CEPREMAP and MAD. Correspondence: F. Portier, CEPREMAP, 142 rue du Chevaleret, 75013 Paris, France. We thank Jean-Pascal Bénassy, Patrick Fève, Pierre-Yves Hénin and an anonymous referee for useful comments. All remaining errors are ours. 
econometrics) have provided new insights about this question since the early eighties.

The $R B C$ view favored technology shocks in the line of Kydland and Prescott [1982] and Long and Plosser [1983]. Non-walrasian models appeared recently more relevant in explaining some macroeconomic regularities: the wage contract framework (Cho and Cooley [1990], Fairise [1995]) or the imperfect competition one ( Rotemberg and Woodford [1992], Hairault and Portier [1993]) underline the role of monetary shocks (pure demand shocks) in the dynamics of industrialized countries.

Hence, the theoretical (microfoundations) and empirical relevance of many shocks (technological, fiscal, monetary) seems established: each recession or recovery might be explained by the realization of these shocks. However, as emphasized by Blanchard [1993], Hall [1993] and Hansen and Prescott [1993], these traditional shocks are not sufficient to account for some macroeconomic episodes, as the 1990-1991 US recession.

It appears that the main cause of that recession was a consumption shock, i.e. a decrease in consumption in relation to its normal determinants. However, since this variable is endogenous, the question of the ultimate source of the shock is left unanswered. It is well-known that the econometrician has less information than the one included in the consumer's information set ${ }^{1}$, since it cannot observe expectations. Two interpretations of this shock are therefore possible: some news on future fundamentals (foresight hypothesis) or some extrinsic uncertainty (animal spirits hypothesis).

Since Keynes, it has been emphasized that changes in demand can arise from investors "animal spirits", i.e. exogenous waves of optimism and pessimism. If these animal spirits models have been considered by most macroeconomists as a theoretical curiosity for a long time, Farmer and Guo [1994] and Gali [1994] have provided such models of business cycles, which are calibrated, simulated and evaluated as $R B C$ models.

While this animal spirits approach has received much attention recently, hasn't it thrown the $R B C$ baby (exogenous shocks on the fundamentals) with the bath water (inability for consumption to lead the cycle)? If we consider the cross correlation over time between output and consumption given by Cooley and Prescott [1995] for the US cycle (Table 1), it appears that the consumption leads output, as the correlation between consumption today and

\footnotetext{
${ }^{1}$ Quah [1992] has already underlined this information problem for explaining the consumption behavior.
} 
output tomorrow is equal to the contemporaneous correlation and superior to the correlation between output today and consumption tomorrow.

Table 1: The Consumption Dynamics in the US Cycle (1954-91)

\begin{tabular}{cccccccccc}
\hline \hline$i$ & -4 & -3 & -2 & -1 & 0 & 1 & 2 & 3 & 4 \\
$\operatorname{corr}\left(\widehat{y}_{t}, \widehat{c}_{t+i}\right)$ & 0.42 & 0.57 & 0.72 & 0.82 & 0.83 & 0.67 & 0.46 & 0.22 & -0.01 \\
\hline \hline
\end{tabular}

The canonical stochastic growth model underestimates the leading behavior of consumption in the cycle as it appears in Cooley and Prescott [1995] (see Table 2). Indeed, in that model, all variables, particularly consumption and output, respond simultaneously to known technological shocks: there is no information in the consumption dynamics which is not yet in current output.

Table 2: The Consumption Dynamics in the optimal growth model

\begin{tabular}{cccccccccc}
\hline \hline$i$ & -4 & -3 & -2 & -1 & 0 & 1 & 2 & 3 & 4 \\
$\operatorname{corr}\left(\widehat{y}_{t}, \widehat{c}_{t+i}\right)$ & 0.34 & 0.46 & 0.59 & 0.72 & 0.84 & 0.50 & 0.22 & 0.02 & -0.12 \\
\hline \hline
\end{tabular}

In this paper, we explore the foresight hypothesis by slightly modifying the canonical $R B C$ model, as presented in Cooley and Prescott [1995]: we add an implementation lag in the technology. Indeed, we assume that agents have today some news on the future level of productivity. Since it takes time to implement inventions -i.e. to transform inventions into innovations that are effectively implemented in the production process ${ }^{2}-$, the observation of inventions today gives information on tomorrow's innovations. But the amount of inventions that will be implemented cannot be known with certainty, and the information that agents have is therefore imperfect ${ }^{3}$. We model this idea by assuming that a stochastic proportion of inventions will

\footnotetext{
${ }^{2}$ We have here in mind the famous distinction made by Schumpeter between the discovery from an inventor and its implementation in the production.

${ }^{3}$ This imperfection of information concerns real shocks and not a mix of real and nominal shocks, as in Lucas [1973].
} 
not be implemented. The "consumption shock" is therefore simply the mirror effect of news on future income ${ }^{4}$.

This particular information structure implies that the exogenous shocks considered cannot be observed. So, we use the Simulated Method of Moments introduced by Duffie and Singleton [1993] to estimate the parameters of the stochastic processes and to test the ability of the model to reproduce the historical consumption dynamics in the US business cycle. Roughly speaking, the Simulated Method of Moments consists in choosing those model parameters' values that produce the best match between empirical and simulated moments. The advantage of this statistical method is first to use the model restrictions in order to estimate the "deep parameters" of the exogenous shocks and second to take into account the moments' uncertainty for testing the model.

The results are in favor of the implementation lag hypothesis: as consumption responds to invention shocks in advance relatively to output, the model is not rejected by US postwar data.

\section{The Model}

We present the most simple " $R B C$ type" model of competitive equilibrium, as described in Cooley and Prescott $[1995]^{5}$, augmented with some delays in the implementation of technological innovations. The economy is populated by $N_{t}$ identical and infinitely living households, with identical preferences defined over consumption and leisure at every date. Population is assumed to grow at rate $\eta$ :

$$
N_{t}=(1+\eta) N_{t-1}
$$

Preferences are assumed to be time additively separable and log-separable with respect to consumption and leisure:

$$
u\left(c_{0}, c_{1}, c_{2}, \ldots\right)=E_{0} \sum_{t=0}^{\infty} \beta^{t}\left((1-\alpha) \log \left(c_{t}\right)+\alpha \log \left(1-h_{t}\right)\right)
$$

Each household has an endowment of time for each period normalized to 1 , which is divided between leisure $\ell_{t}$ and work $h_{t}$. The households own an

\footnotetext{
${ }^{4}$ King and Plosser [1984] have already exploited a rather similar technological lag hypothesis to explain that money Granger causes output.

${ }^{5}$ In particular, we adopt the same notations and functional forms.
} 
initial stock of capital which they rent to firm and may augment through investment. They supply capital and labor to firms that have access to a technology described by the following aggregate production function ${ }^{6}$ :

$$
Y_{t}=e^{z_{t}} K_{t}^{\theta}\left(X_{t} H_{t}\right)^{1-\theta}
$$

where $z_{t}$ is a stationary random productivity parameter with given process and $X_{t}$ a deterministic labor augmenting technical progress that grows at exponential rate $\gamma$ :

$$
X_{t}=(1+\gamma) X_{t-1}
$$

At last, the law of motion for the aggregate capital is given by:

$$
K_{t+1}=(1-\delta) K_{t}+I_{t}
$$

where $I_{t}$ is aggregate investment.

The productive sector can be treated as a single firm that solves a periodby-period profit maximization problem, and whose optimal competitive behavior is to equalize marginal productivities of labor and capital with their respective real market prices.

In this economy where there is only one Pareto-optimal allocation, the optimum derived from a planner's problem can be supported as a decentralized equilibrium. We can therefore recover the competitive equilibrium of this economy from the following planner's problem, where consumption, output, investment and capital are aggregate per capita intensive variables -i.e. divided by the labor augmenting technological progress $X$ and by the population $N$ :

$$
\begin{array}{ll}
\max & E\left[\sum_{t=0}^{\infty} \beta^{t}(1+\eta)^{t}\left((1-\alpha) \log \left(c_{t}\right)+\alpha \log \left(1-h_{t}\right)\right)\right] \\
\text { s.t. } & c_{t}+i_{t}=e^{z_{t}} k_{t}^{\theta} h_{t}^{(1-\theta)} \\
& (1+\gamma)(1+\eta) k_{t+1}=(1-\delta) k_{t}+i_{t}
\end{array}
$$

for a given process of $z$.

\footnotetext{
${ }^{6}$ We use lower-case letters for household variable and upper-case ones for their aggregate counterparts.
} 


\section{The Informational Structure}

In standard $R B C$ models, the process of the total factor productivity is given by:

$$
z_{t}=\rho z_{t-1}+\varepsilon_{t}
$$

where the technological innovation $\varepsilon_{t}$ is instantaneously implemented, and therefore incorporated in the total factor productivity. We assume here that all technological innovations implemented in period $t+\lambda$ have been invented in period $t$, where $\lambda$ is the implementation lag:

$$
z_{t+\lambda}=\rho z_{t+\lambda-1}+\varepsilon_{t}
$$

where $\varepsilon_{t}$ is identically and independently normally distributed with zero mean and variance $\sigma_{\varepsilon}^{2}$. Since there is some delay between invention and implementation, we shall assume that some of the inventions made at period $t$ will eventually become unsuccessful, and will not be implemented $\lambda$ periods later $^{7}$. One way to model such an idea is to assume that in period $t$, agents observe the total amount of inventions $j_{t}$, which is given by

$$
j_{t}=\varepsilon_{t}+v_{t}
$$

but cannot observe separately the $\varepsilon_{t}$ of them that will be implemented in $t+\lambda$, and the $v_{t}$ of them that will not be implemented. We assume that $v_{t}$ is identically and independently normally distributed with zero mean and variance $\sigma_{v}^{2}$, and independent from $\varepsilon_{t}$. The best prediction of the technological innovation before its implementation is then given by the following signal extraction formula:

$$
E\left[\varepsilon_{t} / j_{t}\right]=\chi j_{t} \quad \text { with } \quad \chi=\frac{\sigma_{\varepsilon}^{2}}{\sigma_{\varepsilon}^{2}+\sigma_{v}^{2}}
$$

Agents know that, on average, $\chi \%$ of inventions will be implemented, but the effective percentage of implemented inventions is stochastic, and depends on the realization of $v_{t}$. Such a variation in the proportion of inventions that are implemented can be explained by the inherent uncertainty in the $R \& D$ activity. More generally, this uncertainty can be accounted, as evoked by Hansen and Prescott [1993], by "changes in the legal and regulatory system within a country [that can] induce negative as well as positive changes in technology".

\footnotetext{
${ }^{7}$ For instance, in a case study on optical scanner adoption in grocery stores, Levin, Levin and Meisel [1992] show that there is a fluctuating speed of adoption of a new innovation (scanner).
} 


\section{Calibration and Estimation}

To generate the artificial business cycle from our model, we log-linearize the first order conditions of problem (1) and the equations relative to the informational structure (2) and (3) around the stationary steady-state of the economy, and solve it following Blanchard and Kahn [1980] and King, Plosser and Rebelo [1988]. Given these log-linear rules and a set of deep parameters $\Psi_{1}$, it is straightforward to generate times series for the economic model and to compute a variety of descriptive statistics $\Psi_{2}$, which summarize the cyclical behavior of the artificial economy. For initial values of the state variables $x_{0}$, a vector of the stochastic unobserved shocks $\epsilon_{t}$, and a set of parameters $\Psi_{1}$, one can compute $S$ simulated paths of the variables:

$$
\left\{y_{t}^{n}\left(x_{0}, \Psi_{1}\right) / t=0, \ldots, T ; n=1, \ldots, S\right\}
$$

From these times series, one can compute a set of moments, denoted $\Psi_{2}\left(y_{t}^{n}\left(x_{0}, \Psi_{1}\right)\right)$, conditionally to the value of $\Psi_{1}$. Using the Simulated Method of Moments, the true value of $\Psi_{1}^{0}$ is estimated by choosing a value of $\Psi_{1}$ which minimizes the following objective function, where $\widehat{\Psi}_{2}$ denotes the historical moments:

$$
J_{T}=\left[\widehat{\Psi}_{2}-\frac{1}{S} \sum_{n=1}^{S} \Psi_{2}\left(y_{t}^{n}\left(x_{0}, \Psi_{1}\right)\right)\right]^{\prime} W_{T}\left[\widehat{\Psi}_{2}-\frac{1}{S} \sum_{i=1}^{S} \Psi_{2}\left(y_{t}^{n}\left(x_{0}, \Psi_{1}\right)\right)\right]
$$

where $W_{T}$ is a distance matrix which converges almost surely to $W_{0}=S_{0}^{-1}$, given that $S_{0}$ is limit constant full rank matrix of covariance of estimations errors. We obtain a positive definite matrix using the computation method proposed by Andrews [1991]. To test the model, we impose overidentifying restrictions: the dimension of the function which represents the restrictions that the second order unconditional moments must verify is larger than the number of the estimated first order moments. Since the sample moments are asymptotically normally distributed, and the covariance matrix is robust to both heteroskedasticity and serial correlation, the objective function $J_{T}$ is a statistic distributed as a $\chi^{2}$ with degrees of freedom equal to the number of moments minus the number of parameters being estimated. The estimation of the empirical second order moments $\widehat{\Psi}_{2}$, is done with Hodrick-Prescott cyclical components of the aggregate series, with a smoothness parameter set to 1600 . Each step of the minimization algorithm of the SMM estimator consists in $S=20$ simulations of $T=2 \times T_{s}$ points, where $T_{s}=128$ is the 
sample length ${ }^{8}$.

We restrict the set of estimated parameters to $\Psi_{1}=\left\{\rho ; \sigma_{\varepsilon} ; \sigma_{v}\right.$ or $\left.\chi\right\}$. The other structural parameters are derived from imposing restrictions on our artificial economy which ensure that the model's non stochastic steady state is consistent with a list of standard growth facts for the U.S. economy on the period 1959:1-1990:4. This procedure concerns the following set of parameters: $\theta, \delta, \gamma, \beta, \alpha, \eta$. The list of stylized facts that we consider includes the average growth rate of population and per capita output, the share of total income that is paid to capital, the ratios between the average working time and the total available time, between investment and capital, between capital and output and between consumption and output.

We reconstruct capital, output, consumption and investment series from the measurements that are taken for the U.S. economy. This procedure is extensively described in Cooley and Prescott [1995] and detailed in appendix A. Our data sources are the National Income and Product Accounts (taken from Citibase) and the Fixed Reproducible Tangible Wealth Estimates (provided by Musgrave [1992]).

Roughly speaking, the data correction takes into account the fact that our model does not contain explicit government sector, household production sector, foreign sector and inventories. Our model economy's capital stock does include capital used in all of these sector plus the stock of inventories. We therefore have to impute the flow of services from durables and government capital to measured output. Consumption measure is then composed of consumption of non-durables and services, the imputed rental value of the stock of consumer durables and government consumption, as in Christiano [1988]. Aggregate investment, which includes consumption of consumer durables, changes in inventories, gross fixed investment and net exports, is given by the difference between output and consumption.

From these quarterly series, we compute the figures given in table 3 . The value of $h$ is set according to microeconomic studies (Ghez and Becker [1975], Juster and Stafford [1991]) that show that households allocate about onethird of their discretionary time to market activity. The specific value of .31 is taken from Cooley and Prescott [1995] to allow for comparison.

We therefore calibrate the first set of parameters by choosing them so that

\footnotetext{
${ }^{8}$ See Lee and Ingram [1991] for a detailed exposition and Duffie and Singleton [1993] or Jonsson and Klein [1995] for an application. We used for estimation the GMM MATLAB routine of Ellen R. McGrattan and the SMM ones of Patrick Fève.
} 
Table 3: Growth facts, U.S. Economy, 1959:1-1990:4 (quarterly)

\begin{tabular}{ccccccc}
\hline \hline$\gamma$ & $\eta$ & $\frac{i}{y}$ & $\frac{k}{y}$ & $\frac{c}{y}$ & share of capital income & $h$ \\
.0038 & .0041 & .035 & 8.88 & .69 & .377 & .31 \\
\hline \hline
\end{tabular}

the balanced-growth path of our model matches these growth facts ${ }^{9}$ (table 4).

Table 4: Calibration

\begin{tabular}{ccccccc}
\hline \hline$\theta$ & $\delta$ & $\gamma$ & $\beta$ & $\alpha$ & $\eta$ & $\lambda$ \\
.377 & .0276 & .0041 & .9894 & .6692 & .0038 & 1 \\
\hline \hline
\end{tabular}

To get a simple version of our implementation lag model, we set the lag parameter $\lambda$ equal to 1 , which means that there is a one quarter delay between invention and (actual) innovation.

Since the stochastic dimension of our model is two, we restrict the estimation to a set of moments involving two variables, namely output and consumption. This set of moments is composed of a measure of output variability (standard deviation $\sigma(y)$ ), a measure of consumption persistence (first order serial correlation $\left.\operatorname{corr}\left(c, c_{-1}\right)\right)$ and the instantaneous, one lag and one lead output-consumption correlation $\left(\operatorname{corr}(c, y), \operatorname{corr}\left(c, y_{+1}\right), \operatorname{corr}\left(c, y_{-1}\right)\right)$. Thus, $\widehat{\Psi}_{2}$ is defined by:

$$
\widehat{\Psi}_{2}=\left\{\sigma(y), \operatorname{corr}\left(c, c_{-1}\right), \operatorname{corr}(c, y) ; \operatorname{corr}\left(c, y_{+1}\right) ; \operatorname{corr}\left(c, y_{-1}\right)\right\}
$$

\section{Estimation results and propagation mech- anisms}

Estimations results are given in tables 5 and 6 . The first order serial correlation of the total factor productivity estimated is around of 0.95 , which is

\footnotetext{
${ }^{9}$ Given the estimations of growth rates and ratios given in table 3 , we compute the values of model's parameters according to the following equations: $\delta=\frac{i}{k}+1-(1+\gamma)(1+\eta)$, $\beta=\frac{1+\gamma}{\frac{\theta y}{h}+1-\delta}, \frac{\alpha}{1-\alpha}=\frac{(1-\theta) y}{c} \frac{1-h}{h}$.
} 
the value traditionally considered: the exogenous persistence is high but the process is stationary. Moreover the estimation reveals the relative volatility between the shocks $\epsilon$ and $v$ : on average $72 \%$ of inventions are implemented, and $28 \%$ are not.

Table 5: Estimated Aggregate Uncertainty Parameters

\begin{tabular}{ccc}
\hline \hline$\rho$ & $\sigma_{\varepsilon}$ & $\sigma_{v}$ \\
0.9462 & 0.0075 & 0.0047 \\
\hline \hline
\end{tabular}

The Simulated Method of Moments allows us to test if all the restrictions used to estimate the structural parameters $\Psi_{1}$, are verified. The overidentifying test shows that the theoretical moments implied by the model estimation can not be rejected by the data. These statistical results are clearly in favor of the implementation lag model. The dynamics of the consumption appears well reproduced. The lead and lag correlations between consumption and output are close to their historical counterparts. The correlations between $\widehat{c}_{t}$ and $\hat{y}_{t+i}(-1 \leq i \leq 1)$ are positive, the correlation between $\widehat{c}_{t}$ and $\widehat{y}_{t+1}$ is higher than the correlation between $\hat{y}_{t}$ and $\widehat{c}_{t+1}$ and close to the instantaneous one $(\text { table } 6)^{10}$.

Table 6: Estimation of Moments and Test for Goodness of Fit

\begin{tabular}{ccc}
\hline \hline Moments & Empirical & Model \\
$\sigma(y)$ & .0150 & .0144 \\
$\operatorname{corr}\left(c, c_{-1}\right)$ & .87 & .83 \\
$\operatorname{corr}(c, y)$ & .78 & .76 \\
$\operatorname{corr}\left(c, y_{+1}\right)$ & .75 & .73 \\
$\operatorname{corr}\left(c, y_{-1}\right)$ & .69 & .66 \\
\hline$J_{T}$ & \multicolumn{2}{c}{.9638} \\
p-value $\left(\chi^{2}(2)\right)$ & \multicolumn{2}{c}{$61 \%$} \\
\hline \hline
\end{tabular}

These results come from both the implementation lag and the information structure of the model -i.e. the internal propagation mechanisms. They are

\footnotetext{
${ }^{10}$ Let us notice that the implementation lag model performs better on this aspect than the Gali [1994] animal spirits model, where the maximum correlation is instantaneous, and the magnitude of lead and lag correlations inverted.
} 
illustrated on figures 1 and 2 (see appendix B).

Since information is imperfect at the period of the shocks, the instantaneous responses to the two shocks are strictly alike. Since the invention shock is perceived by agents as being likely to affect future technology, it increases agents anticipated wealth. Therefore, the standard permanent income mechanism applies: consumption increases. This wealth effect also leads to a slight decrease in worked hours and output. In a model without implementation lag, the wealth effect is dominated by a consumption-leisure substitution effect, since labor productivity is instantaneously increased by the technological shock: hours and output increase. Since the technological shock is only announced in our setup, total factor productivity is left unchanged, no substitution effect occurs. Instantaneously, the labor supply curve shifts upwards, the labor demand curve is unchanged and consequently, labor productivity (and real wage) increases. Indeed, the implementation lag acts as if the future technological shock was today a demand shock: the labor demand curve is not yet affected, even if it will be tomorrow. While the output is close to its stationary value -i.e. is not yet affected, the consumption is already increased by an invention shock. These propagation mechanisms due to the implementation lag hypothesis imply that consumption is a more leading indicator of output than in the optimal growth model.

One must underline that, relatively to a model without imperfect information, the responses of output and consumption to an implemented invention shock are modified, since agents do not know that this invention will be effectively implemented. The imperfect information hypothesis reduces, ceteris paribus, the initial response of consumption, as the income flows anticipated are lower, and explains why the correlation between consumption today and output tomorrow is close the contemporaneous one.

After period one, when the true values of $v$ and $\varepsilon$ are revealed, the two sets of IRF display different patterns. A non-implemented invention shock has no effect on the fundamentals (the path of $A$ is flat on figure 2), and the economy converges gradually back to the steady state. These shocks lower the simulated correlation between consumption today and output tomorrow. On the opposite, when an implemented invention shock occurs, labor and output increase in the second period for the same reason than in a standard $R B C$ model. This result explains the fact that consumption leads the output. 


\section{Conclusion}

In this paper, we have shown that including some time to implement and some imperfect information can significantly improve the fit of the canonical $R B C$ model by making consumption a more leading indicator of output. This purely technological model cannot be seen as a benchmark model of business cycle, but we think that such implementation lags should be added in more realistic model with non-walrasian features and demand shocks.

\section{References}

D. ANDREws. Heteroskedasticity and autocorrelation consistent covariance matrix estimation. Econometrica, 59(3):817-58, 1991.

O.J. Blanchard and C. Kahn. The solution of linear difference models under rational expectations. Econometrica, 48(5):1305-1311, July 1980.

O.J. Blanchard. Consumption and the recession of 1990-1991. American Economic Review, 83(2):270-274, May 1993.

A. Cho and T. Cooley. The Business Cycle with Nominal Contracts. Mimeo, University of Rochester, 1990.

L. Christiano. Why does inventory investment fluctuates so much? Journal of Monetary Economics, 21:247-80, 1988.

J. Cochrane. Shocks. Working paper 4698, National Bureau of Economic Research, April 1994.

T. Cooley and E. Prescott. Economic growth and business cycle. In T. Cooley, editor, Frontiers of Business Cycle Research, chapter 1, pages 1-38, Princeton University Press, Princeton, New Jersey, 1995.

D. Duffie and K. Singleton. Simulated moments estimators of markov models of asset prices. Econometrica, 61(4):929-52, 1993.

X. FAIRISE. Nominal wage contracts and the short run dynamics of real wages. In P.Y. Hénin, editor, Advances in Business Cycle Research, chapter 7, pages 241-86, Springer, Berlin, 1995. 
R. Farmer and J.T. Guo. Real business cycles and the animal spirits hypothesis. Journal of Economic Theory, 63(1):42-72, 1994.

J. GALI. Monopolistic competition, business cycles, and the composition demand. Journal of Economic Theory, 63(1):73-96, 1994.

G. Ghez And G. Becker. The Allocation of Time and Goods over the Life Cycle. Columbia University Press, New-York, 1975.

J.O. Hairault and F. Portier. Money, new-keynesian macroeconomics and the business cycle. European Economic Review, 37(8):1533-1568, December 1993.

R. Hall. Macro theory and the recession of 1990-1991. American Economic Review, 83(2):275-279, May 1993.

G. Hansen and E. Prescott. Did technology shocks cause the 1990-1991 recession? American Economic Review, 83(2):280-286, May 1993.

G. Jonsson And P. KLein. Stochastic Fiscal Policy and the Swedish Business Cycle. Working paper, Institute for International Economic Studies, Stockholm University, April 1995.

F. Juster and F. STAFford. The allocation of time: empirical findings, behavior models and problems of measurement. Journal of Economic Literature, 29:471-522, 1991.

R. King And C. Plosser. Money, credit and prices in a real business cycle. American Economic Review, 74(3):363-380, June 1984.

R. King, C. Plosser and S. Rebelo. Production, growth and business cycles I. Journal of Monetary Economics, 21(2/3):196-232, March-May 1988.

F. Kydland and E. Prescott. Time to build and aggregate fluctuations. Econometrica, 50(6):1345-1370, November 1982.

B. Lee and B. Ingram. Simulation estimation of time series models. Journal of Econometrics, 47:197-205, 1991. 
S. LeVin, S. LeVin AND J. Meisel. Market structure, uncertainty, and intrafirm diffusion: the case of oiptical scanners in grocery stores. Review of Economic and Statistics, 74(2):345-50, 1992.

J. Long And C. Plosser. Real business cycle. Journal of Political Economy, 91(1):39-69, February 1983.

R. LUCAS. Some international evidence on output inflation tradeoff. American Economic Review, 63(3):326-334, June 1973.

J. Musgrave. Fixed reproductible tangible wealth in the united states, revised estimates. Survey of Current Business, 72(1):106-135, january 1992.

D. QUAH. The relative importance of permanent and transitory components: identification and some theoretical bounds. Econometrica, 60(1):107-118, January 1992.

J. Rotemberg And M. Woodford. Oligopolistic competition and the effect of aggregate demand on economic activity. Journal of Political Economy, 100(6):1153-1207, 1992.

\section{Appendix A: The Data}

The way we reconstruct aggregate series for capital, output, investment and consumption is described in Cooley and Prescott [1995]. We simply give here the Citibase and Survey of Current Business code of the series that we use and how are $Y, C, I$ and $K$ computed. We send the reader to Cooley and Prescott [1995] and Christiano [1988] for a detailed exposition. All series unit is the billion of 1987 dollars. All slanted series code are Citibase ones. The three following series are taken from Musgrave [1992]: FPC: Total fixed private capital (table 4), DGOC: Durable goods owned by consumers (table 4), GOFC: Total government-owned fixed capital. These three stock series, and the population one ( $P A N 1 \eta)$ have been transformed into quarterly data using a linear interpolation. Since these series are stocks, that are not subject to high frequency movements, we think that the interpolation does not add too much noise. All flow series that we use are quarterly ones. Private capital income $Y_{K P}$ is given by: $Y_{K P}=(G P R E N J+G P J V A+G N I N T)$ $/$ NIDEF $+\theta_{P}(G R P O J /$ NIDEF $+G N N P Q-G Y Q)+G C C J Q$, where $\left.\theta_{P}=[(G P R E N J+G P J V A+G N I N T) / \mathrm{NIDEF})+G C C J Q\right] /[G N P Q-$ 
$(G R P O J / \mathbf{N I D E F}+G N N P Q-G Y Q)]=.377$ is the share of capital income in total income and NIDEF $=G Y / G Y Q$ is the national income deflator. The idea in that computation of private capital income is that it is the sum of unambiguous capital income (rental income + corporate profits + net interest) plus a share of the ambiguous component of capital income (proprietors income + net national product - national income), this share being the share of capital income in measured gnp. The interest rate $i$ is therefore computed as $i=\left(Y_{K P}-G C C J Q\right) /(\mathbf{F P C}+G L Q)=.0251$, and the depreciation rate of private capital is given by $\delta_{P}=G C C J Q / \mathbf{F P C}=$ .0122. It must be noticed that we do not include any estimates of the value of land in our measure of private capital since it seems poorly measured (see Cooley and Prescott [1995], footnote 12). This explains why our estimation of interest rate is higher than Cooley and Prescott's one. From the law of motion of capital, deflating by output on a balanced-growth path, one gets the depreciation rate of public capital $\delta_{G}=(G G N D Q+G G O D Q+$ $G G S D Q) /$ GOFC) - $\gamma_{Y}$, where $\gamma_{Y}$ is the growth rate of $G N P Q=.0139$ and the depreciation rate of consumer durables $\delta_{D}=(G C D Q /$ DGOC $)$ $\gamma_{Y}=.0583$. One can therefore compute the service flows of public capital $\left(Y_{G}\right)$ and consumer durable $\left(Y_{D}\right): Y_{G}=\left(i+\delta_{G}\right)$ GOFC and $Y_{D}=\left(i+\delta_{D}\right)$ DGOC. Measured output is given by $Y=G N P Q+Y_{D}+Y_{G}$, consumption by $C=(G C Q-G C D Q)+(G G E Q-(G G N D Q+G G O D Q+G G S D Q))+$ $Y_{D}-\delta_{D}$ DGOC, and investment by $I=Y-C$.

\section{Appendix B: Figures}


Figure 1: Response to an Implemented Invention

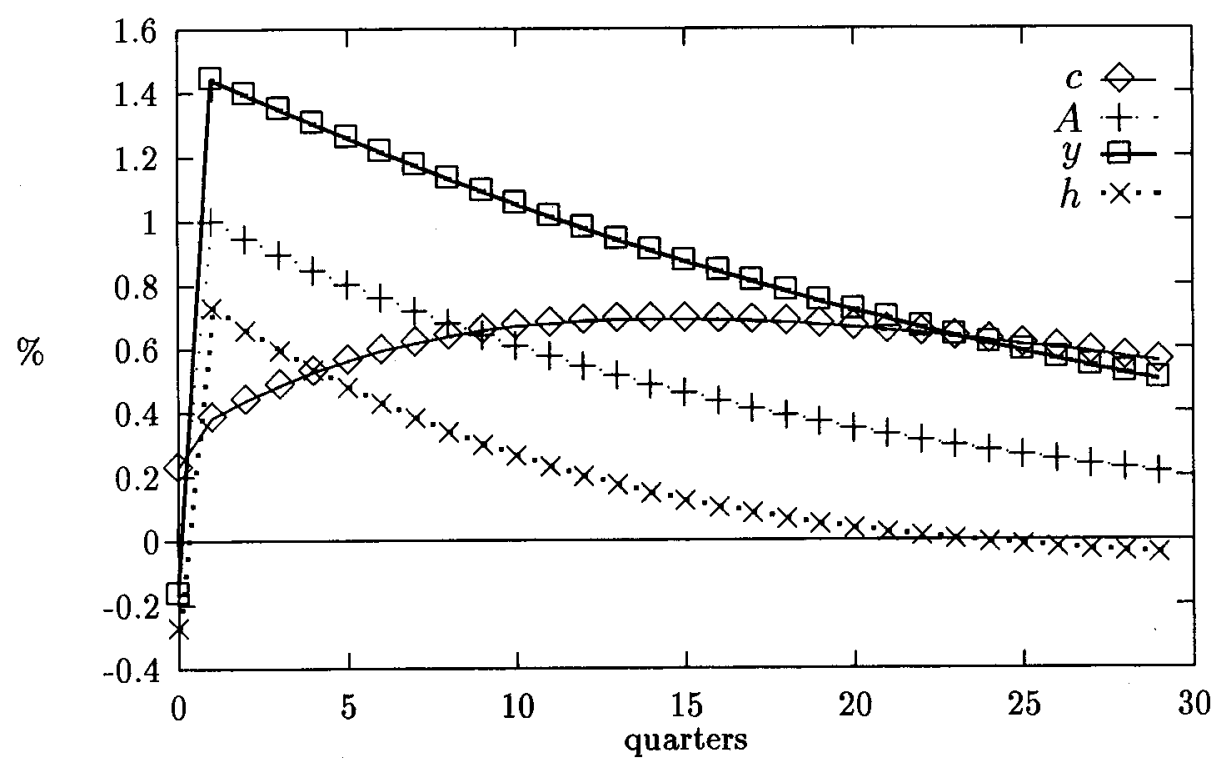


Figure 2: Response to a Non-Implemented Invention

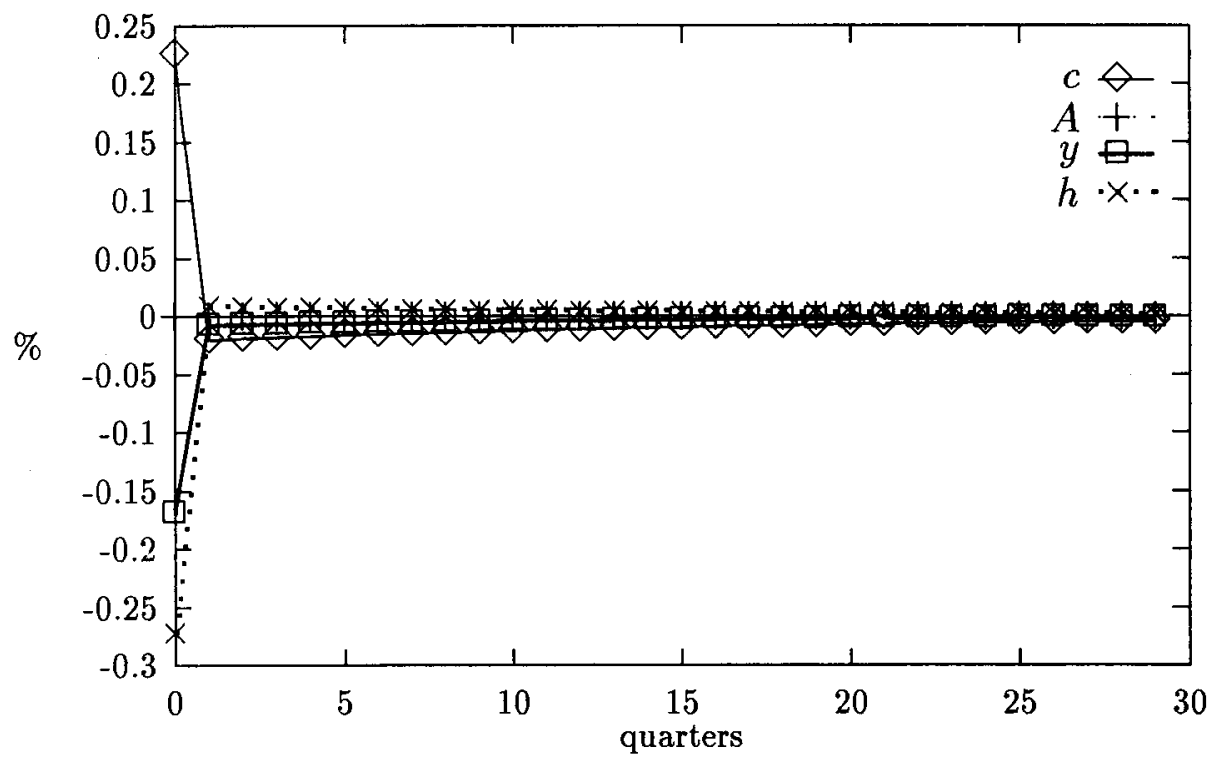

